\title{
GRAFFITI E IGUALDAD DE GÉNERO: LA ARTISTA ICAT Y EL PROYECTO EDUCATIVO DEL IES TRASSIERRA (CÓRDOBA)
}

\author{
Laura Luque Rodrigo \\ Universidad de Jaén. Dpto. Historia del Arte
}

\section{Resumen}

La ciudad ha sido a lo largo de la historia un espacio dedicado al hombre, la mujer encontraba su espacio dentro de la casa. Sin embargo, poco a poco la mujer comienza a ocupar el espacio urbano, también desde el arte. El arte urbano resulta un medio de comunicación magnífico puesto que llega a todos los ciudadanos, lo que le da un poder inmenso si se quiere usar como medio para educar en cuanto a cultura visual colectiva. En el texto trataremos de casos concretos como la artista ICAT y el IES Trassierra.

Palabras-clave: ARTE URBANO; GÉNERO; IGUALDAD; EDUCACIÓN; CIUDAD

\section{GRAFFITI AND GENDER EQUALITY: THE ARTIST ICAT AND THE EDUCATIONAL PROJECT OF THE IES TRASSIERRA (CÓRDOBA)}

\section{Abstract}

The city has been throughout history a place dedicated to man, meanwhile women found her place in the house. However, bit by bit, women begun to occupy the urban space, including the art expression. Urban art is a powerful media because it reaches to all citizens, which gives to it an immense power if used to educate people in terms of providing a collective visual culture. In the text we will deal with specific cases such as the artist ICAT and the IES Trassierra.

Keywords: STREET ART; GENDER; EQUALITY; EDUCATION; CITY

\footnotetext{
Luque Rodrigo, Laura. "Graffiti e igualdad de género: La artista Icat y el proyecto educativo del IES Trassierra (Córdoba)". AusArt 6 (1): 73-82. D0I: 10.1387/ausart.19156
}

\section{AUSART}




\section{INTRODUCCIÓN}

"Por definición el espacio público es aquel que el habitante de la ciudad-habitual o esporádico- puede utilizar sin más limitaciones que ciertas ordenanzas legales y ateniéndose a unas normas de decoro aceptadas por el conjunto social" (Fernández 1988, 17-39). La ciudad es el espacio en el que se desarroIla la vida pública, en la plaza, se concentran los edificios que representan los poderes, por lo que adquiere una especial significación.

La arquitectura ha sido la que tradicionalmente ha estado presente en el espacio público, es de todas las artes la más universal, pues participa de la vida cotidiana de cada persona, en todo momento y en cada rincón. Con la irrupción del graffiti y posteriormente de otros tipos de manifestaciones artísticas urbanas, los artistas comienzan a apropiarse del espacio urbano (Luque Rodrigo 2016, 117), pues arquitectura y urbanismo habían dejado nulo margen de opinión con respecto a la construcción de los espacios públicos a los artistas (Szmulewicz 2017, 4).

Las actividades del hombre a lo largo de la historia y las culturas se desarrollan fuera del espacio doméstico, mientras que la casa quedaba unido a lo femenino, sin embargo, en la actualidad el espacio urbano es tanto del hombre como de la mujer. La pintura, a lo largo de los siglos nos ha mostrado a la mujer en su espacio habitual, el doméstico y sólo salía para aparecer como modelo, musa o en prostíbulos ya en el siglo XIX, tal y como se desprende de estudios como los de Patricia Mayayo (2007), John Berger (1972), Ángeles Caso $(2005 ; 2016 ; 2017)$ o Luque y Mantas $(2009,48)$, entre otros. Esta cosificación de la mujer de alguna forma se mantiene en la ciudad actual, por ejemplo a través de las vallas publicitarias que constantemente nos presentan mujeres ejerciendo estereotipos, frente a esto es interesante descubrir como el arte urbano entra en conflicto visual con estas imágenes proponiendo otros modelos. Estas imágenes, que cualquier viandante consume sin necesidad de entrar en un museo o galería de arte, contribuyen a la educación visual de la ciudadanía. Se ha entendido que la forma de hacer la ciudad más igualitaria era mediante la incorporación de mujeres arquitectas y urbanistas (Rodríguez 2008), en España han surgido colectivos que proponen cambiar el modelo de ciudad para que esté pensada para ser vivida y no sólo para moverse y trabajar, como Mujeres Urbanistas o la Fundación María Aurelia Campmany (Ortiz Guitart 2007). Laura Elkin (2016) retoma el término flâneuse, usado por Janet Wolf (1985) como variante de flâneur, paseante callejero, que sólo tiene versión 
masculina, en referencia a las mujeres que cambiando el modo de moverse por el espacio urbano, pueden intervenir en la organización del mismo.

\section{ARTE URBANO, CUESTIONES DE GÉNERO Y CIUDAD}

En la década de los 60 , coincidiendo con la Segunda Ola Feminista, nacen los estudios de género dentro de la historia del arte, así como se desarrolló una corriente artística representada por mujeres que emplearán el arte como instrumento de denuncia, usando especialmente la performance. De ese primer momento de denuncia, se pasa a la exaltación de lo femenino, con el empleo del propio cuerpo como instrumento de trabajo (Varela 2005). Los años 80 vuelven a ser de denuncia y algunas artistas como Bárbara Kruger empiezan a salir a la calle (Gutiérrez 2017). Progresivamente, en la última década del siglo XX y sobre todo durante el siglo XXI se comienzan a plantear nuevas subjetividades.

En este sentido han emergido artistas realmente interesantes que plantean el arte con una utilidad pública o educacional, combatiendo incluso nuestra cultura visual con nuevas imágenes a través de la fotografía especialmente, que amplían nuestro imaginario personal y colectivo, de manera que se normalicen situaciones o se reflexione sobre temas de actualidad que de otra forma pasan desapercibidos especialmente para los medios. Por ejemplo, Valle Galera, Mara León, Verónica Ruth Frías, Claudia Frau o Yolanda Domínguez, entre otras.

Pero, ¿qué presencia tienen en el ámbito urbano? Si bien es cierto que algunas de estas artistas saltan con frecuencia al espacio urbano, es a través del arte urbano como las mujeres toman las calles dejando su huella en la piel de los edificios que generan nuestras calles, componiendo el paisaje que transitamos a diario. 


\subsection{LA SITUACión de LAS MUJeRes artistas DENTRO DEL ARTE URBANO}

Las mujeres se sumaron al graffiti desde sus inicios en los años 70 en EEUU, una de las artistas más conocidas de ese periodo es Lady Pink, que rápidamente se unió al movimiento feminista de la época. En el resto del mundo la incorporación de las mujeres al mundo del arte urbano fue más tardía, ya en la década de los 80 , tanto en el continente americano como europeo, además de Oceanía, Asia y África, donde la actividad se limita prácticamente a Sudáfrica. Swoon cuenta como por su estilo y su nombre la gente no imaginaba cuál era su sexo y que mostraban su asombro al verla, con cierto tono de tristeza narra cómo la gente se fijaba en ella más por el hecho de ser mujer y graffitera que por su propia obra y eso le molestaba mucho (Ganz 2006, 9). En España, Diana Prieto, cofundadora de Madrid Street Art Project, en una entrevista realizada para Mujeres en las Artes Visuales (2013), confiesa que hay más nombres masculinos dentro del arte urbano, pero como puede suceder en otros ámbitos aun hoy día. Parece pues, que las desigualdades siguen vigentes. Además de ser menos, parece que las mujeres empiezan con mayor edad a escribir en los muros y se retiran antes (Gonçalvez de Paula 2008).

\subsection{ARtistas y proyectos para la igualdad}

Lo primero que hay que plantearse es si el arte, en general, puede servir para cambiar el mundo. Ciertamente existen proyectos y artistas que logran cambios. Por ejemplo, en Afganistán hay mujeres pintando los muros en pro de las propias mujeres, como la artista Shamsia Hassani', que trata con su arte de traer cambios positivos a la sociedad, mediante mujeres con burka. En un país donde las mujeres no tienen derechos y el graffiti no existía, la labor de Shamsia Hassani cobra aún más fuerza. Otra mujer artista, Faith47, realiza sus obras con un sentido de espiritualidad a través del cual reivindica los derechos de las mujeres, movida por el contexto que vive en su país.

En este sentido, son varias las artistas urbanas que trabajan el tema de la igualdad de género en sus obras, con frecuencia en contra del maltrato como la brasileña Panmela Castro. En España destacan artistas como Nuria Mora que en una entrevista realizada para Realidades Inexistentes (2011) comentaba que el arte urbano es un mundo machista; Julieta XLF, que considera que si bien el arte urbano está invadido por publicidad, es un buen medio de comunicación ${ }^{2}$; o el artista Vermibus, que sustituye carteles publicitarios de las marquesinas donde se cosifica a las mujeres, por el mismo cartel intervenido 
en el que borra la imagen. La artista francesa Miss Van dibuja mujeres hipersexualizadas e infantiles, voluptuosas y sensuales, si bien lo hace como una provocación al situarlas encima de obras realizadas por hombres, a los que representa como animales de compañía.

La mayor parte de los proyectos que se realizan desde las instituciones públicas se enlazan con la temática de la violencia de género y con frecuencia se enmarcan dentro de las actividades desarrolladas para el día de la mujer, son ejemplo de ello la exposición 'Pasos sin violencia' celebrada por el Ayuntamiento de Casariche en 2016, el proyecto 'Ni una víctima más de violencia de género" organizado por la Asociación Zoes Barrio del Oeste de Salamanca, el programa del Ayuntamiento de Getafe "Practicando Igualdad, grafitis contra el machismo" de 2016 o la cesión del Ayuntamiento de Valencia de 90 metros de muro en 2017 con motivo del día de la mujer, entre otro muchos proyectos. También fuera de España, como el certamen "Muchachitas pintoras" que se celebró en Chile en $2017^{3}$, con la idea de visibilizar el trabajo que hacen mujeres artistas del graffiti. El grupo Abusa Crew -formado por las artistas Anís y Wend-, afirmaba en una entrevista que "es importante deconstruir el machismo instaurado dentro del arte urbano" (2016). También en México se llevó a cabo en 2015 una experiencia similar, aunque en este caso buscaba luchar contra la violencia sobre las mujeres y eran hombres los que pintaban bajo el hastag "NacíHombreNoMacho" (en Mural.com).

Un proyecto destacado en cuanto al uso del arte urbano para promover la igualdad de género se llevó a cabo en el madrileño barrio de Lavapiés en 2015, patrocinado por Madrid Street Art Project ${ }^{5}$. Tres artistas, Hyuro, Pincho y El Rey de la Ruina fueron seleccionados para pintar tres murales entorno a esta temática. Hyuro, realizó la obra "Reciprocidad", cargada de simbolismo nos habla de igualdad dentro de la pareja. En la obra de Hyuro en general, se representan mujeres reales, las que vemos en nuestro día a día, trabajadoras e incansables (Pérez Mendoza 2016). Por su parte, El Rey de la Ruina, realizó la obra "Socialmente iguales, humanamente diferentes, totalmente libres", tomando la frase de Rosa Luxemburgo (1871-1919), socialista que entre otras cosas luchó por el voto universal. Por último, Pincho, realizó la obra "Tejidos de barrio" en el mercado de San Fernando, que presenta a una mujer flotando, enlaza con diferentes casas. En este proyecto encontramos tres claves interesantes, por un lado la representación de la mujer real presente en la cotidianeidad, por otro la vinculación con las grandes luchadoras y en tercer lugar la importancia del contexto en que se realiza la obra. Y podríamos añadir algo 
más, no sólo son mujeres las que trabajan y se preocupan por la igualdad de género.

\subsection{LA ARTISTA ICAT Y SU OPINIÓN SOBRE EL BINOMIO ARTE URBANO Y GÉNERO}

La artista jiennense Mónica Gómez ‘cat’”, realiza es donde con frecuencia aparecen mujeres. Su obra, influenciada por artistas como "Den XL, Sax, Faith47, Mad C, Hera, Fafi, Animalitoland, Shiro, (...) la fotógrafa Martha Cooper y la cineasta Selina Miles" ${ }^{7}$, tiene en cuanto a estética mucho del mundo del cómic y la ilustración, las mujeres aparecen fuertes, extrapolándolo al mundo de la animación infantil, son similares al personaje de Sara Lavrof en Tadeo Jones.

La artista considera que el arte es fundamental para cambiar el mundo "desde lo más concreto como puede ser dar un sentido a la vida de una persona que decide dedicarse a desarrollar su arte (...) También puede cambiar la realidad de grandes grupos de personas. Por ejemplo: realizar un proyecto de rehabilitación de un barrio mediante una pintura colectiva, realizar una exposición

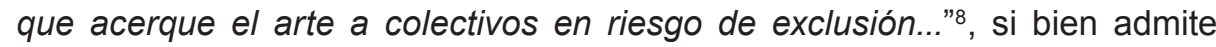
que también puede ser negativo porque puede provocar un proceso de gentrificación. Confiesa además que a ella le ha ayudado personalmente en su autoestima puesto que sufrió bullying en el colegio. Son especialmente interesantes los murales donde pinta a mujeres spray en mano, diseñando sus propios graffitis, un medio para reivindicar el papel de las mujeres dentro del mundo del arte urbano: "Con mi obra me centro mucho en la mujer, gran parte de mis murales incluyen mujeres (muchas de estas con un spray en la mano). Con esto pretendo mostrar nuestra presencia dentro del movimiento graffiti y acercarlo a las niñas especialmente" , puesto que el arte urbano "está en la calle, al alcance de todo el mundo. Es el medio perfecto para llegar a toda la población"10.

Icat considera que si hay machismo en el arte urbano es porque existe en la sociedad, pero cree que está menos presente que en otras disciplinas. Al mismo tiempo, opina que "existe sororidad", no porque tengamos que luchar contra una opresión, pero si por dar visibilidad y acercar nuestra disciplina a otras mujeres que puedan estar interesadas y no se atrevan a dar el paso"12, este punto es interesante puesto que vuelve a incidirse en el tema de la visibilidad. Es decir, el problema de las mujeres no es la imposibilidad de acceder, sino que la propia invisibilización de las mujeres que existen en el sector hace que a otras mujeres artistas les genere dudas con respecto a entrar 
en este ámbito. Además, considera que el arte urbano puede empoderar a las mujeres puesto que "es una disciplina donde se aprende día a día y se va evolucionando la técnica, la forma de pensar y de afrontar nuevos retos. Por tanto, cada día nos hace más fuertes en todos los sentidos"13. En cuanto a la posibilidad de que el arte urbano sirva como contraposición a las vallas publicitarias con imágenes estereotipadas de mujeres en roles tradicionales, es decir, extrapolar el término publicitario de femvertising al arte urbano, opina que "una imagen es la forma más rápida de dar un mensaje. En la calle el arte urbano compite por espacio con las vallas publicitarias"14, es decir, existiendo dicha competencia sí que se podría pensar en confrontar las imágenes publicitarias con el arte urbano de manera que se cree una lucha visual en cuanto a la representación de las mujeres.

\subsection{EL ARTE URBANO PARA EDUCAR EN IGUALDAd dE GÉNERO}

Puesto que el arte urbano es un buen canal para transmitir conceptos como la igualdad de género, es evidente que puede servir para educar desde las aulas. Un ejemplo sería el desarrollado en 2015 en Cártama y Alahurín el Grande, donde se organizó un programa de arte urbano para formar a jóvenes en Igualdad de Género, llamado Igualarte ${ }^{15}$, contando con la artista Btoy (Flickr Btoy).

El IES Trassierra de Córdoba creó en 2011 el Concurso de Graffitis por la Igualdad "convencidos de que era necesario trabajar la igualdad entre hombres y mujeres de una manera diferente. Después de pensar diferentes maneras de hacerlo decidimos que a través de un concurso de grafitis, al ser una modalidad artística muy "joven" y con espíritu rompedor o subversivo, les podía resultar atractivo"16. Dentro del centro las funciones se reparten entre un equipo de profesorado y cuentan con la colaboración del EOE y el CEP, además de la delegación de cultura de la Junta de Andalucía. Por su parte, desde que el concurso se ha convertido en provincial, cuentan con el apoyo económico de Cajasur.

El mayor objetivo que han conseguido que es a lo largo de los años el número de chicas y chicos que participan en el concurso se vaya igualando: "Pienso que a lo largo de estos años el alumnado en general va tomando conciencia de los temas de igualdad, pero aún queda mucho camino por recorrer, sobretodo en algunos colectivos que son menos receptivos a esta temática. Pero si destacaríamos un aspecto: hemos logrado una participación más igualitaria de chicas y chicos en este tipo de arte. El mundo del grafiti es considerado típicamente masculino y si no se discrimina a priori a las chicas, pocas mujeres 
destacan o son reconocidas en 'ese mundillo'. En nuestro concurso, a lo largo de estos años ha ido aumentando la participación de chicas y sus trabajos seleccionados como finalistas"17.

Los graffitis se realizan en paneles de contrachapado de $2,44 \times 1,22$ y botes de spray, también se les permite emplear plantillas y pinceles. Otro de los logros interesantes del proyecto, es que los jóvenes se hayan interesado por otras iniciativas como Sexjoven o microrrelatos por la igualdad de género ${ }^{18}$.

\section{CONCLUSIONES}

El Arte Urbano, por ser una manifestación artística que incide directamente sobre la ciudad, puede contribuir a su transformación, o al menos, en las personas que la transitan, proponiendo imágenes diferentes que favorezca, en este caso, la igualdad de género, o de sexos, a través de la cultura visual colectiva. De esta forma, entra en competencia con la publicidad que inunda las marquesinas y que tienden a perpetuar los roles tradicionales y la cosificación de las mujeres. No obstante, resulta significativo que también exista machismo dentro del arte urbano, por lo que deben realizarse propuestas que sirvan para dar mayor visibilidad a las artistas. Especialmente interesantes son los usos del arte urbano en los centros educativos.

\section{Referencias}

Abusa Crew. 2016. "Es importante deconstruir el machismo instaurado dentro del arte urbano". Entrevista por Carla González Carrasco. Quid.cl, 3 dic. https://quid.cl/2016/12/03/abusa-crew-es-importante-deconstruir-el-machismo-instaurado-dentro-del-arte-urbano/

Arrazola Tojal, Txaro. 2016. "Plataforma A, colectivo vasco para la incorporación normalizada de las mujeres en el Sistema del arte". Extramurs 3(5):289-318

Berger, John. 1972. Ways of seeing. London: Penguin

Caso, Ángeles. 2005. Las olvidadas, una historia de mujeres creadoras. Barcelona: Planeta

- . 2016. Ellas mismas: Autorretratos de pintoras: Desde la Prehistoria hasta las vanguardias. Oviedo: Libros de la letra azul.

— . 2017. Grandes maestras: Mujeres en el arte occidental: Renacimiento-siglo XIX. Oviedo: Libros de la letra azul 
Elkin, Laura. 2016. Flâneuse: Women walk the city in Paris, New York, Tokyo, Venice, and London. London: Chatto \& Windus

Fernández Arenas, José, coord. 1988. Arte efímero y espacio estético. Fernando Torrijos et al. Barcelona: Anthropos

Ganz, Nicholas. 2006. Graffiti mujer: Arte urbano de los cinco continentes. Emilia Pérez Mata, trad. Barcelona: Gustavo Gili

Gonçalves de Paula, Priscilla Danielle. 2008. "Graffiti hip hop femenino en España a finales del siglo XX: La singularidad como significancia". Tesis Univ. Politècnica de Valencia

Gutiérrez, María Laura. 2017. "Arte, tecnología, género y espacio público; Un análisis a través de las obras de Jenny Holzer y Bárbara Kruger". Prometeica 15:17-30

Luque Rodrigo, Laura \& Rafael Mantas Fernández. 2009. "La mujer en el espacio pintado: De la edad moderna a la contemporánea". Asparkía 21: 47-64

- . 2016. "Arte relacional en la calle: Casos de conservación colectiva". Revista del GEIIC 10: $117-25$

Mayayo Bost, Patricia. 2007. Historias de mujeres, historias del arte. Madrid: Cátedra

Mora, Nuria. 2011. "Entrevista a Nuria Mora". Realidades Inexistentes. Por Jorge Dueñas Villamiel. http://www.realidadesinexistentes.com/entrevista-a-nuria-mora [Acceso 19 oct. 2017]

Ortiz Guitart, Anna. 2007. "Hacia una ciudad no sexista: Algunas reflexiones a partir de la geografía humana feminista para la planeación del espacio urbano". Territorios 16-17:11-28

Pérez Mendoza, Sofía. 2016. "Las heroínas invisibles de Hyuro". El Diario.es, 9 feb. https:// www.eldiario.es/cultura/arte/Hyuro-arte-urbano-desigualdad-genero_0_482252132.html

Prieto Martín, Diana. 2013. "Entrevista a una de las fundadoras de la Asociación Madrid Street Art Project, Diana Prieto Martín". M-arte y cultura visual. Por María José Magaña. http:// www.m-arteyculturavisual.com/2013/06/05/binomio-arte-urbano-y-mujer/ [Acceso 20 oct. 2017]

Quirosa García, Victoria; Luque Rodrigo, Laura. 2015. "Arte útil para la sociedad. Consideraciones en torno a seis artistas del siglo XXI en España". De Arte 14: 249-61

Rodríguez Calatayud, Nuria. 2008. "La mujer en los márgenes, la memoria femenina en la ciudad". En Diálogos urbanos, confluencias entre arte y ciudad, I Congreso Internacional Arte y Entorno, 279-88. Valencia: Centro de Investigación Arte y Entorno UPV

Serrano Martínez, Cecilia. 2016. "El arte urbano como instrumento de empoderamiento y visibilización: El festival de Asalto”. Comunitania 11:9-26

Szmulewicz R., Ignacio. 2017. "La ciudad al margen: Más allá del arte público comunitario: Un Proyecto de Ángela Ramírez". Tórax 1(1): 1-15

Varela Menéndez, Nuria. (2005) 2017. Feminismo para principiantes. Barcelona: Ediciones B

Wolff, Janet. 1985. The invisible flâneuse. Women and the literature of modernity. London: Routledge 


\section{Notas}

1 "Shamsia Hassani". Kabul Art Project. http://www.kabulartproject.com/artists/shamsia-hassani/ [Acceso 20 oct. 2017]

2 "Entrevista a Julieta XLF". Femimagazine, 19 oct. 2012. http://www.Irmcidii.org/entrevista-a-la-artista-julieta-xlf/

3 'Muchachitas Pintoras', el primer festival de arte urbano con enfoque de género en la RM". www.cultura.gob. Agenda cultural Ministerio de las Culturas, las Artes y el Patrimonio, Gobierno de Chile. 06 abril 2017 [Acceso 19 oct. 2017]

${ }^{4}$ www.mural.com (México) [Acceso 20 oct. 2017]

${ }^{5}$ Madrid Street Art Project. http://madridstreetartproject.com/ [Acceso 20 oct. 2017]

${ }^{6}$ Blog Icat. https://mynameisicat.blogspot.com.es/ [Acceso 20 oct. 2017]

${ }^{7}$ Entrevista realizada vía correo electrónico entre el 27 de septiembre y el 18 de octubre. Sirve para las siguientes citas del apartado.

8 Íbid.

9 Íbid.

10 Íbid.

11 "Agrupación que se forma por la amistad y reciprocidad entre mujeres que comparten el mismo ideal y trabajan por alcanzar un mismo objetivo", RAE.

${ }^{12}$ Entrevista realizada vía correo electrónico entre el 27 de septiembre y el 18 de octubre. Sirve para las siguientes citas del apartado.

13 Íbid.

14 Íbid.

15 "Igualarte 2015". www.valledelguadalhorce.com. http://www.valledelguadalhorce.com/igualarte2015/ [Acceso 20 oct. 2017]

${ }^{16}$ Entrevista realizada vía mail entre el 27 de septiembre y el 18 de octubre a Trinidad Berral orientadora del centro IES Trassierra y a la coordinadora del Plan de Igualdad Mercedes Fernández.

17 Íbid.

${ }^{18}$ Entrevista realizada a Victoria García Rodríguez, profesora del departamento de Artes Plásticas del IES Trassierra entre el 27 de septiembre y el 3 de octubre vía email. 